\title{
Secreted frizzled-related protein 4 promotes brown adipocyte differentiation
}

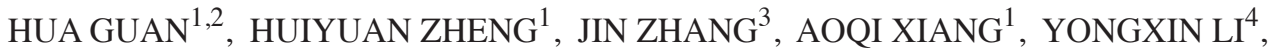 \\ HUADONG ZHENG ${ }^{1}$, LIXIAN XU ${ }^{2}$, ENQI LIU ${ }^{5}$ and $\mathrm{QI} \mathrm{YU}^{1}$ \\ ${ }^{1}$ Shaanxi Key Laboratory of Ischemic Cardiovascular Diseases and Institute of Basic and Translational Medicine, \\ Xi'an Medical University, Xi'an, Shaanxi 710021; ${ }^{2}$ Department of Anesthesiology; ${ }^{3}$ Preventive Dentistry, \\ The Fourth Military Medical University Stomatological Hospital, Xi'an, Shaanxi 710032; \\ ${ }^{4}$ Department of Cardiovascular Surgery, The First Affiliated Hospital of Xi'an Jiaotong University; \\ ${ }^{5}$ Laboratory Animal Center, Xi'an Jiaotong University Health Science Center, Xi'an, Shaanxi 710061, P.R. China
}

Received May 11, 2020; Accepted March 8, 2021

DOI: $10.3892 / \mathrm{etm} .2021 .10069$

\begin{abstract}
Secreted frizzled-related protein 4 (SFRP4) is a member of the SFRP family that contains a cysteine-rich domain homologous to the putative Wnt-binding site of frizzled proteins. In the present report, the effects of SFRP4 on murine brown adipocyte differentiation were evaluated, which exhibited an intrinsic capacity to differentiate with high efficiency. Brown preadipocytes were isolated from the scapular region of brown adipose tissue, which showed that the overexpression of recombinant active SFRP4 protein at three concentrations $(1,10$ and $100 \mathrm{ng} / \mathrm{ml})$ significantly increased the expression of adipocyte differentiation-associated genes (C/EBP $\alpha, \mathrm{C} / \mathrm{EBP} \beta, \mathrm{UCP}-1, \mathrm{PRDM} 16, \mathrm{PGC} 1 \alpha$ and GLUT4) in a dose-dependent manner compared with the control group. Secondly, adiponectin protein expression was significantly inhibited in a dose-independent manner, while leptin was increased in brown adipocytes by incubation with the high
\end{abstract}

Correspondence to: Dr Qi Yu, Shaanxi Key Laboratory of Ischemic Cardiovascular Diseases and Institute of Basic and Translational Medicine, Xi'an Medical University, 1 Xinwang Road, Xi'an, Shaanxi 710021, P.R. China

E-mail: qiyu6028@hotmail.com

Abbreviations: Ab, antibody; BAT, brown adipocyte tissue; Cidea, cell death-inducing dffa-like effector a; DMEM/F12, Dulbecco's modified Eagle's medium/nutrient mixture F-12; FABP4, fatty acid binding protein 4; FBS, foetal bovine serum; GOI, gene of interest; GLUT4, solute carrier family 2 (facilitated glucose transporter), member 4; PPAR $\gamma$, peroxisome proliferator activated receptor $\gamma$; PGC-1a, peroxisome proliferator-activated receptor $\gamma$, coactivator $1 \alpha$; PRDM16, PR domain containing 16; SFRP, secreted frizzled related proteins; T3, triiodothyronine; UCP-1, uncoupling protein 1; WAT, white adipose tissue

Key words: SFRP4, brown adipocyte, differentiation, interleukin- $1 \beta$, inflammation concentration $(100 \mathrm{ng} / \mathrm{ml})$ of SFRP4. Thirdly, the role of interleukin-1 $\beta$ (IL-1 $\beta$ ) was investigated in brown adipocytes and discovered that IL-1 $\beta$ cannot induce SFRP4 mRNA expression in brown adipocytes, similar to human islet cells. These data suggested that SFRP4-treated brown adipocytes represent a valuable in vitro model for the study of adipogenesis and indicated that SFRP4 served various functions during brown adipocyte differentiation.

\section{Introduction}

Adipose tissue is an important endocrine organ that regulates energy metabolism and nutrition homeostasis (1). There are at least two distinct types of adipose tissue in mammals: White adipose tissue (WAT) and brown adipose tissue (BAT) (2). The main function of WAT is to store energy in the form of triglycerides, and WAT plays an important role in regulating systemic metabolism and insulin sensitivity (3). In contrast, BAT burns energy through non-shivering thermogenesis and visually appears brown because it contains a high number of mitochondria (4). In particular, uncoupling protein-1 (UCP-1) is expressed specifically in BAT and controlled by the concerted action of neural and hormonal signals to activate the program responsible for fuel oxidation and thermogenesis (5). It is worth mentioning that high-resolution imaging technology suggested that BAT not only exists in rodents but also assumes certain biological functions in adult bodies $(6,7)$. This new discovery provides scientists with insight into the role of BAT in regulating energy consumption, restoring glucose homeostasis and decreasing obesity. Therefore, the molecular regulatory mechanism of the differentiation of brown adipocytes has been a research hotspot.

As a member of secreted frizzled-related proteins (SFRPs), SFRP4 has a cysteine-rich region at the C-terminal and a netrin-like domain motif at the N-terminal, which is highly conserved and binds to frizzled or Wnt membrane proteins (8). As a secreted cytokine, SFRP4 plays an important role in obesity (9), insulin resistance (10) and type 2 diabetes (11). In addition, bioinformatics data analysis showed that the 
expression level of SFRP4 in fat tissue of obese pigs was significantly higher compared with that of lean pigs (12). Thirdly, previously published research findings demonstrated that the expression pattern and function of SFRP4 has adipose tissue depot specificity in subcutaneous and visceral adipose tissue in mice (13). However, little is known about the role and function of SFRP4 in the formation and thermogenesis of BAT which plays an important role in lipid metabolism, obesity and energy consumption (4).

Considering the involvement of SFRP4 in obesity, insulin resistance and type 2 diabetes, the present study aimed to determine the role of SFRP4 in brown adipocyte differentiation. Hence, the effects of SFRP4 on cell morphology, lipid droplet accumulation, and adipogenesis-specific protein expression in brown adipocytes were examined. The present study demonstrated that SFRP4 expression is associated with inflammatory markers, and its release from islets is stimulated by interleukin-1 $\beta$ (IL-1 $\beta$ ).

\section{Material and methods}

Brown preadipocyte isolation and culture. Brown preadipocytes were obtained from the interscapular BAT of mice (age, 3 weeks old; C57BL/6J mice) and isolated by digestion with collagenase dispersion as described previously (14). In the present study, the cell pool from different animals (20 mice each time) were used and the experiment was repeated three times. In detail, mice were purchased from Beijing Vital River Laboratory Animal Technology (Beijing Vital River Laboratory Animal Technology Co., Ltd.) and monitored the health of animals every day before execution. All animals housed in an air-conditioned room under a 12-h light and 12-h dark cycle. Food and water were allowed ad libitum. Five mice in a cage were euthanized by injecting carbon dioxide into the cage at a gas exchange rate of $28 \%$ container volume/min. C57BL/6 mice aged 3 weeks lost consciousness within 4-5 min, and died within 8-10 min, which was consistent with the requirements of the National Institutes of Health (NIH) guidelines (15). The characteristics of death included no spontaneous breathing for 2-3 min and absence of blink reflex. The cell culture experiment was continued for six months. BAT was collected from the scapular region of mice under sterile conditions and washed in phosphate-buffered saline three times.

BAT was collected from the scapular region of mice under sterile conditions and washed in phosphate-buffered saline three times. The tissue mass was cut with scissors into $\sim 1-\mathrm{mm}^{3}$ sections and digested with $1 \mathrm{mg} / \mathrm{ml}$ type I collagenase at $37^{\circ} \mathrm{C}$ for $40 \mathrm{~min}$ in a shaking water bath. Then, the digestion of the cell suspension was stopped by Dulbecco's modified Eagle medium/nutrient mixture F-12 (DMEM/F12) medium supplemented with $10 \%$ foetal bovine serum (FBS). Isolated cells $\left(1 \times 10^{6} / \mathrm{ml}\right)$ were seeded in 6 -well plates with DMEM/F12 medium supplemented with $10 \%$ FBS and $1 \%$ Pen/Strep (day 4). The cell proliferation state is very important for murine adipocyte differentiation. The cells were seeded in the dish at day-4, and the cell density was $\sim 70 \%$. At day-2, the percentage of cell confluence was $80-90 \%$, and the cells reached contact inhibition at day 0 .

For BAT differentiation in vitro, the cells were treated with differentiation medium containing $1.7 \mu \mathrm{M}$ insulin and
$1 \mathrm{nM}$ triiodothyronine (T3) from day-2 to 0 and induced with induction medium supplemented with $1.7 \mu \mathrm{M}$ insulin, $1 \mathrm{nM} \mathrm{T3}, 0.5 \mathrm{mM}$ isobutylmethylxanthine and $1 \mu \mathrm{M}$ dexamethasone from day 0 to 2 . Differentiating cells were kept in differentiation medium from day 2 to 8 (16). The differentiation pattern of brown adipocytes is shown in Fig. 1. The animal experiments were strictly following the guidelines of animal experiment in Xi'an Medical University, which was adapted from the Guide for the Care and Use of Laboratory Animals (NIH) (15). The Laboratory Animal Administration Committee of Xi'an Medical University approved all animal experiments (Institutional Animal Care and Use Committee; approval no. XYJZS-201806025-8).

Oil Red $O$ staining. Dishes were washed twice with phosphate-buffered saline and fixed with $4 \%$ paraformaldehyde for $30 \mathrm{~min}$ at room temperature. Then, the cells were stained with Oil Red $\mathrm{O}$ working solution at room temperature for $30 \mathrm{~min}$, washed twice with distilled water, observed and photographed under an inverted optical microscope (magnification, x200; Nikon Eclipse TE300; Nikon Corporation). The Oil Red O area was quantified by the image analysis system (WinRoof Mitani Co.).

Reverse transcription-quantitative $(R T-q) P C R$ analysis. Total RNA from adipocytes was extracted using TRIzol plus (Invitrogen; Thermo Fisher Scientific, Inc.), and cDNA was synthesized with PrimeScript ${ }^{\mathrm{TM}}$ RT Master mix using the following temperature protocol: $37^{\circ} \mathrm{C}$ for $15 \mathrm{~min}, 85^{\circ} \mathrm{C}$ for $5 \mathrm{sec}$ and $4^{\circ} \mathrm{C}$ for $20 \mathrm{~min}$ (Takara Biology Inc.). qPCR analysis was performed using the StepOne Plus Real-time PCR system (Thermo Fisher Scientific, Inc.). The number of transcripts was quantified, and each sample was normalized according to its b-actin content. Relative expression of the gene of interest $(\mathrm{GOI})$ was determined using calculation $=2^{\text {(Cq } \beta \text {-actin }}$ gene-Cq GOI) (13). PCR primer sequences are shown in Table SI.

Western blotting. Brown adipocytes were lysed in cell lysis buffer (HEPES 50 mM; NaCl 150 mM; Triton X-100 1\%; $\mathrm{Na}_{3} \mathrm{VO}_{4} 1 \mathrm{mM}$; NaF 30 mM; $\mathrm{Na}_{4} \mathrm{P}_{2} \mathrm{O}_{7} 10 \mathrm{mM}$; EDTA $10 \mathrm{mM}$; aprotinin $1 \mu \mathrm{g} / \mathrm{ml}$; antipain $1 \mu \mathrm{g} / \mathrm{ml}$; pepstatin $1 \mu \mathrm{g} / \mathrm{ml}$; leupeptin $1 \mu \mathrm{g} / \mathrm{ml}$; benzamidine $2.5 \mathrm{mM}$; AEBSF $0.5 \mathrm{mM}$; $\mathrm{pH}=7.4$ ) at $4^{\circ} \mathrm{C}$, and the resultant supernatants were subjected to western blotting. As adipocytes contain high lipid content, an ultrasonic crusher was used to break up the cells and the protein concentration was quantified using a BCA test kit, according to the manufacturer's procedure. Briefly, protein samples (20 $\mu \mathrm{g}$ /lane) were separated on 10\% SDS-polyacrylamide gels and then transferred to Sequi-blotting polyvinylidene fluoride membranes (Bio-Rad Laboratories, Inc.). The blot membranes were incubated with blocking buffer [5\% non-fat milk powder dissolved in TBST (0.1\% Tween-20) buffer solution] for $2 \mathrm{~h}$ at room temperature and then with the following primary antibodies for $2 \mathrm{~h}$ at room temperature $(\mathrm{Ab})$ : Anti-adiponectin (cat. no. AF1119; R\&D Systems, Inc.; 1:1,000), anti-leptin (cat. no. AF498; R\&D; 1:1,000), anti-fatty acid-binding protein (FABP4) (cat. no. AF1443; R\&D; 1:1,000), anti-UCP-1 (cat. no. MAB6158; R\&D; $1: 1,000)$, or anti- $\beta$-tubulin (cat. no. ab15246; Abcam; 1:2,000). The membranes were washed and incubated with horseradish peroxidase-conjugated 
Brown adipocyte differentiation pattern

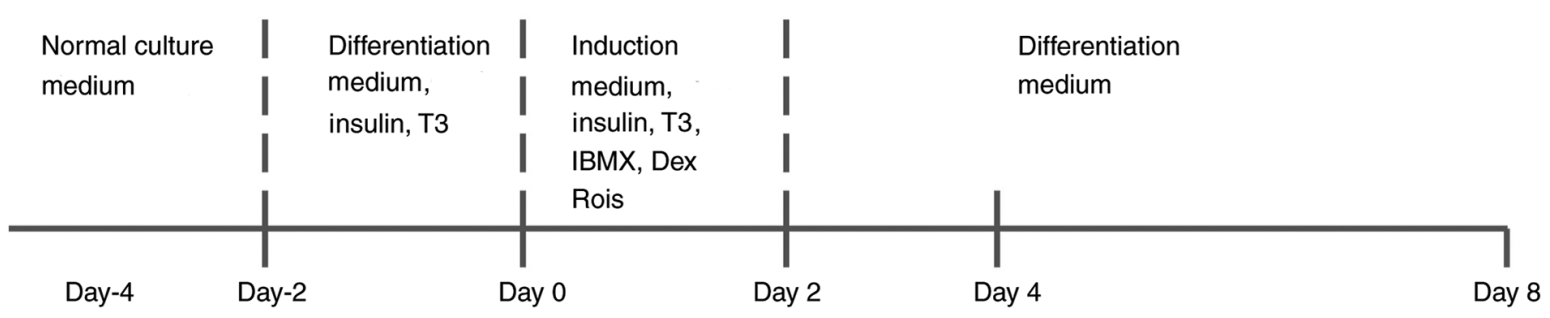

Figure 1. Brown preadipocytes were cultured to confluence (day 0) in maintenance medium containing $10 \%$ foetal bovine serum, $1 \mathrm{nM}$ (T3) and $1.7 \mu \mathrm{M}$ insulin and then induced in differentiation medium (DMEM/F12 with 10\% FBS) supplemented with $0.5 \mathrm{mM}$ isobutylmethylxanthine, $1 \mu \mathrm{M}$ dexamethasone, $1.7 \mu \mathrm{M}$ insulin and $1 \mathrm{nM}$ T3 for 2 days and then induced to differentiate for another 6 days in growth medium. T3, 3,3',5-triiodo-L-thyronine. IBMX, isobutylmethylxanthine; Dex, dexamethasone; Rois, Rosiglitazone.
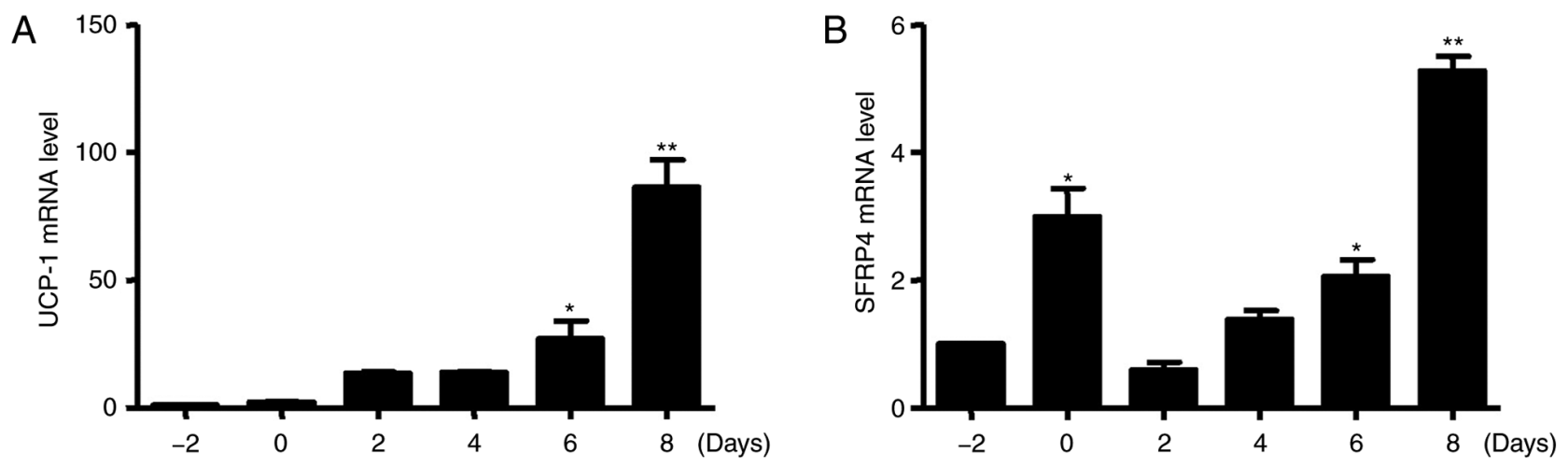

Figure 2. Expression pattern of SFRP4 and UCP-1 in brown adipocyte differentiation. (A) Brown adipocyte-specific gene UCP-1 mRNA expression was analysed by RT-qPCR. (B) SFRP4 mRNA expression was analysed by RT-qPCR. Cells were induced to differentiate into mature brown adipocytes for 8 days, and then, cells were collected every other day. Data are expressed as the mean \pm SEM. $n=3$ for each group. ${ }^{*} \mathrm{P}<0.05 ;{ }^{* *} \mathrm{P}<0.01$ vs. control. SFRP4, secreted frizzled related protein 4; UCP-1, uncoupling protein 1; RT-qPCR, reverse transcription-quantitative PCR.

secondary $\mathrm{Ab}$ for $2 \mathrm{~h}$ at room temperature. Then, Immobilon reagent (EMD Millipore) was used for visualization with an LAS-400 Lumino image analyser (Fujifilm Wako Pure Chemical Corporation). Blots were quantitatively analysed by Quantity One 4.5.2 (Bio-Rad Laboratories, Inc.).

SFRP4 and IL-1 $\beta$ treatment. Brown preadipocytes were treated with recombinant mouse SFRP4 (cat. no. 50053-M08H; 1,10 or $100 \mathrm{ng} / \mathrm{ml}$ ) or IL-1 $\beta$ (cat. no. 50101-MNAE; $25 \mathrm{ng} / \mathrm{ml}$ ) active protein (Sino Biological Company) at the dedicated time points as described previously (17).

Statistical analysis. All data are expressed as the mean \pm SEM. Statistical analyses were performed using either Student's t-test when the $F$ value was equal or Welch's t-test when the $F$ value was not equal. Four groups of data were analysed by one-way ANOVA followed by Tukey's multiple-comparison procedure. For unequal variances, data were evaluated by the Kruskal-Wallis test. In order to avoid the false positive error in the data analysis, Bonferroni correction was performed as the post-hoc tests following Kruskal-Wallis tests. $\mathrm{P}<0.05$ was considered to indicate a statistically significant difference.

\section{Results}

Expression pattern of SFRP4 in brown adipocyte differentiation. Primary cultured brown preadipocytes were isolated from the scapular region of mice, and the addition of differentiation medium promoted the expression of gene cascade and induced differentiation into mature brown adipocytes. The isolated cells exhibited increased numbers of Oil red $\mathrm{O}$ stained lipid vesicles with culturing, and most preadipocytes were filled with numerous lipids after 8 days of differentiation; this suggests that in the process of culturing, brown adipocytes mature from precursors (data not shown). Next, RT-PCR was performed to investigate the brown adipocyte-specific gene expression pattern. As expected, the expression of UCP-1 was markedly increased during brown adipogenesis (Fig. 2A). At the same time, the level of SFRP4 mRNA was significantly increased after incubation with inducers from day-2 to day 0 , but decreased at day 2 . The level of SFRP4 mRNA was significantly increased after incubation with inducers from day 6 to 8 (Fig. 2B).

SFRP4 promotes primary brown preadipocyte differentiation. To explore whether SFRP4 is involved in the management of brown adipogenic differentiation, the effect of SFRP4 during brown adipogenesis was detected. Brown preadipocytes were isolated from murine BAT and SFRP4 was overexpressed using three different concentrations of recombinant active protein $(1,10$ and $100 \mathrm{ng} / \mathrm{ml})$. Interestingly, primary brown adipocytes formed more lipid droplets, and the differentiation rate was up to $\sim 90 \%$ with the treatment of high-dose SFRP4 recombinant protein, 


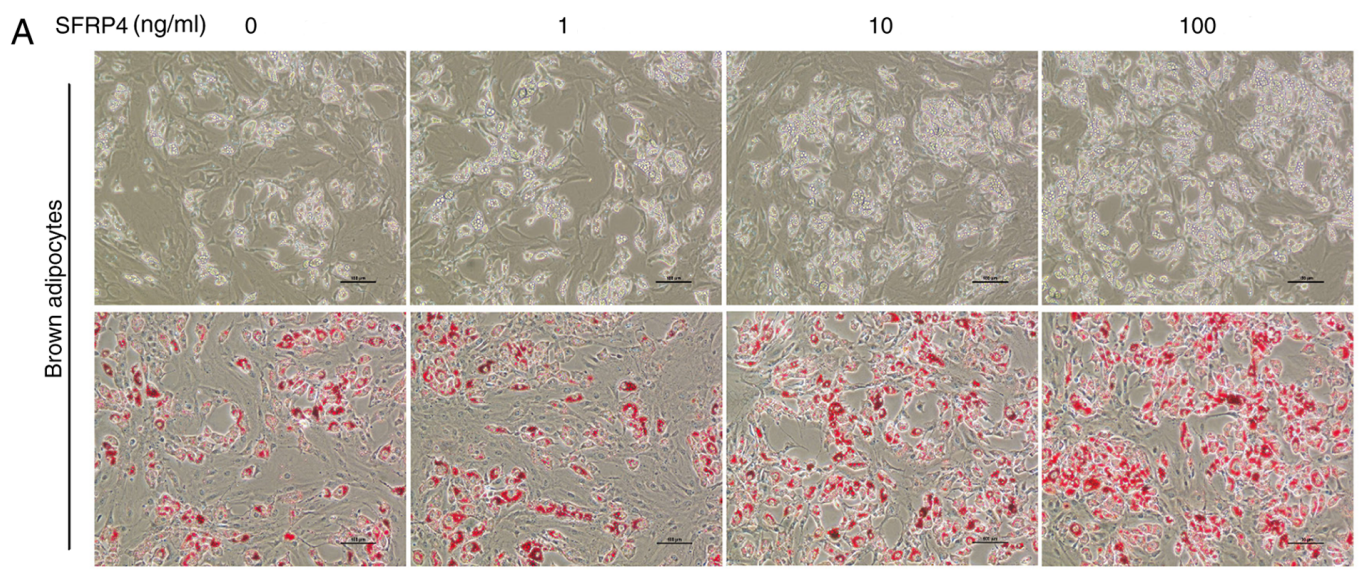

B
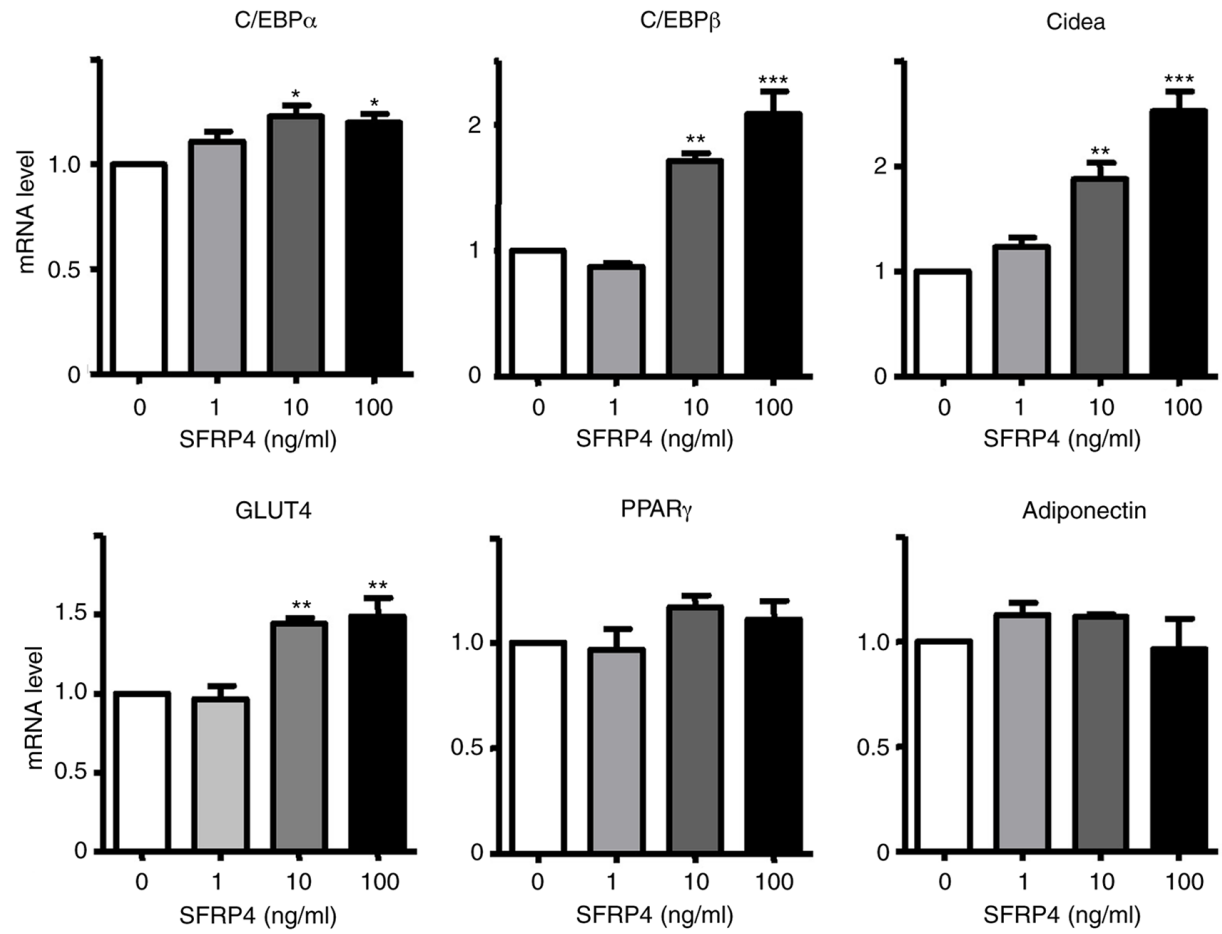

UCP-1
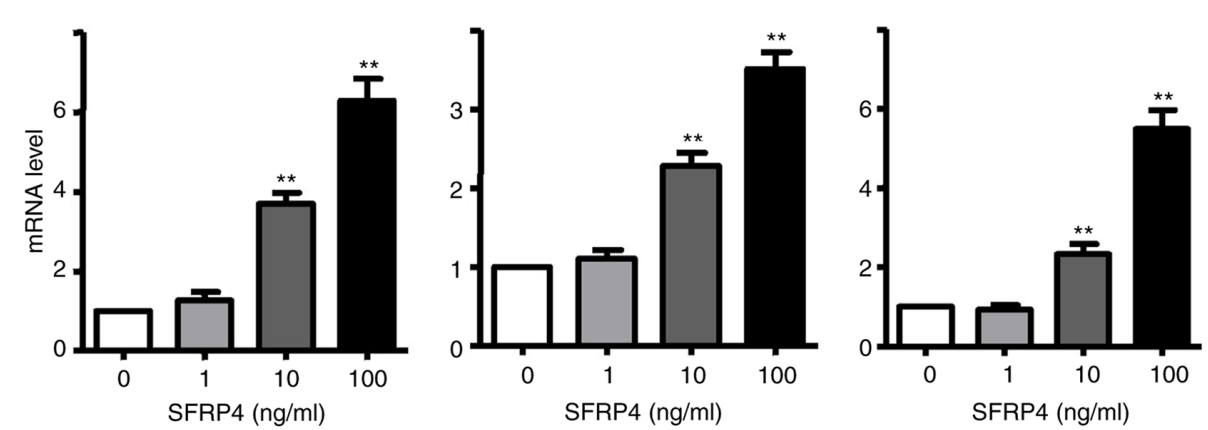

Figure 3. SFRP4 promotes brown preadipocyte differentiation in a dose-dependent manner. Brown preadipocytes incubated with SFRP4 during maintenance and differentiation in different concentration gradients of 1,10 and $100 \mathrm{ng} / \mathrm{ml}$. (A) Photomicrographs show Oil Red O staining of cells on day 8 of differentiation. Magnification, x200. (B) mRNA expression of the brown adipocyte adipogenic markers C/EBP $\alpha, \mathrm{C} / \mathrm{EBP} \beta$, GLUT4 and Cidea, UCP-1, PGC-1 $\alpha$ and PRDM16 were assessed by reverse transcription-quantitative PCR. At a concentration of $100 \mathrm{ng} / \mathrm{ml}$ SFRP4, the levels of C/EBP $\alpha, \mathrm{C} / \mathrm{EBP} \beta, \mathrm{GLUT} 4 \mathrm{and}$ Cidea were all 1.5-fold higher compared with those in the absence of SFRP4. Data are expressed as the mean $\pm \mathrm{SEM} ; \mathrm{n}=4$ for each group. ${ }^{*} \mathrm{P}<0.05 ;{ }^{*} \mathrm{P}<0.01$; ${ }_{* * * *} \mathrm{P}<0.001$ vs. control. SFRP4, secreted frizzled related protein 4; UCP-1, uncoupling protein 1 ; C/EBP $\alpha / \beta$, CCAAT/enhancer-binding protein $\alpha / \beta$; GLUT4, solute carrier family 2 (facilitated glucose transporter), member 4; Cidea, cell death-inducing dffa-like effector a; PGC-1 $\alpha$, peroxisome proliferator-activated receptor $\gamma$, coactivator $1 \alpha$; PRDM16, PR domain containing 16.

as the differentiation rate of the control group was just $\sim 70 \%$ (Fig. 3A and B). Adipogenic markers of brown adipocytes were assessed by RT-qPCR and western blotting (Figs. 3 and 4). Solute carrier family 2 (facilitated glucose 

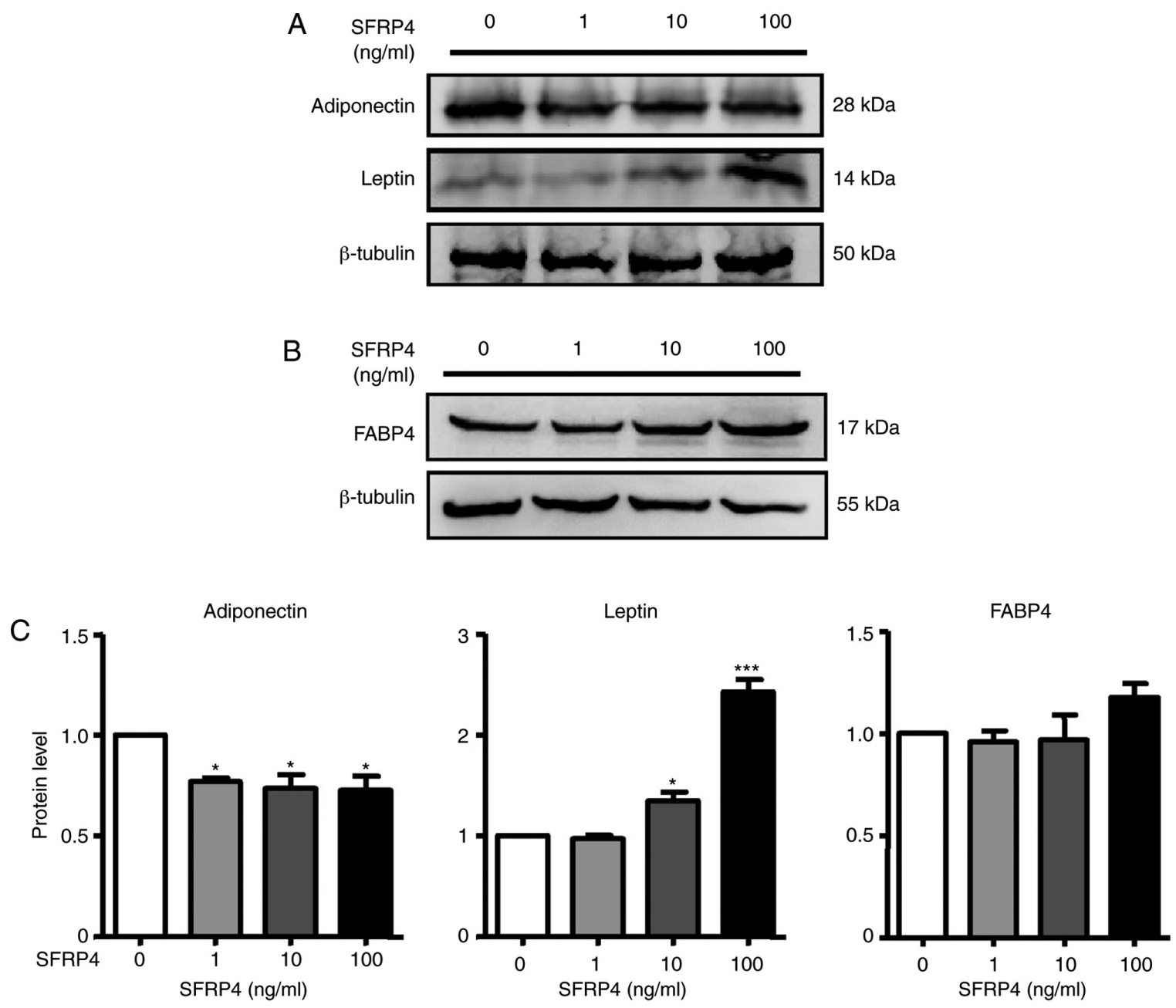

Figure 4. SFRP4 regulates adipogenic protein expression in brown adipocytes. (A) Adiponectin and leptin protein expression were measured by western blotting. (B) FABP4 protein expression was measured by western blotting. (C) Quantification of western blot analysis. With SFRP4 treatment, adiponectin protein expression was significantly inhibited in a dose-independent manner, and leptin protein expression was 1.4- and 2.5 -fold at concentrations of 10 and $100 \mathrm{ng} / \mathrm{ml}$, respectively, after SFRP4 treatment. Data are expressed as the mean \pm SEM. $\mathrm{n}=4$ for each group. ${ }^{*} \mathrm{P}<0.05,{ }^{* * *} \mathrm{P}<0.001$ vs. control. SFRP4, secreted frizzled related protein 4 ; FABP4, fatty acid-binding protein 4

transporter), member 4 (GLUT4), cell death-inducing dffa-like effector a (Cidea), CCAAT/enhancer binding protein $\alpha(\mathrm{C} / \mathrm{EBP} \alpha), \mathrm{C} / \mathrm{EBP} \beta, \mathrm{UCP}-1$, peroxisome proliferator-activated receptor $\gamma(\operatorname{PPAR} \gamma)$, coactivator $1 \alpha(\mathrm{PGC}-1 \alpha)$ and PR domain containing 16 (PRDM16) mRNAs were significantly increased. For a more detailed examination of SFRP4, western blotting we also performed to analyse protein expression. The results revealed that SFRP4 significantly inhibited adiponectin protein expression in a dose-independent manner but increased leptin secretion at concentrations of 10 and $100 \mathrm{ng} / \mathrm{ml}$ (Fig. 4A and C). These results clearly implied that SFRP4 induces brown preadipocyte differentiation into mature adipocytes.

\section{IL-1 $\beta$ has no effect on SFRP4 expression enhancement} in brown adipocytes. A previous study demonstrated that SFRP4 expression correlated with inflammatory markers and was stimulated by IL-1 $\beta$ in islets (11). To further establish the regulation of IL-1 $\beta$ in the context of SFRP4, the effect of SFRP4 on the sensitivity to IL-1 $\beta$ was evaluated. The results show that the brown adipocyte differentiation efficiency was significantly decreased after incubation with
IL-1 $\beta$ at a concentration of $25 \mathrm{ng} / \mathrm{ml}$. The upper images of Fig. 5A show the cell morphology by inverted phase contrast microscopy. To evaluate the accumulation of lipid droplets during brown adipocyte differentiation, Oil Red O staining was performed (Fig. 5A). As expected, lipid accumulation was decreased by treatment with IL-1 $\beta$ (Fig. 5A). However, no changes were observed in SFRP4 mRNA expression (Fig. 5B). Quantification of this effect revealed a significant fact that IL-1 $\beta$ cannot influence SFRP4 expression in brown adipocytes.

$\mathrm{C} / \mathrm{EBP} \alpha, \mathrm{C} / \mathrm{EBP} \beta$ and PPAR $\gamma$ mRNA expression levels were not changed after treatment, while IL-1 $\beta$, Cidea and UCP-1 mRNA expression were significantly decreased after treatment compared with the control condition (Fig. 6A). After treatment with IL-1 $\beta$, UCP-1 protein expression was consistent with the change in mRNA expression. However, adiponectin protein expression was significantly increased compared with the control group in brown adipocytes (Fig. 6B). These data demonstrated that although the inflammatory factor IL-1 $\beta$ has antiadipogenic function, it did not promote SFRP4 expression in adipocytes as it did in islet cells. 

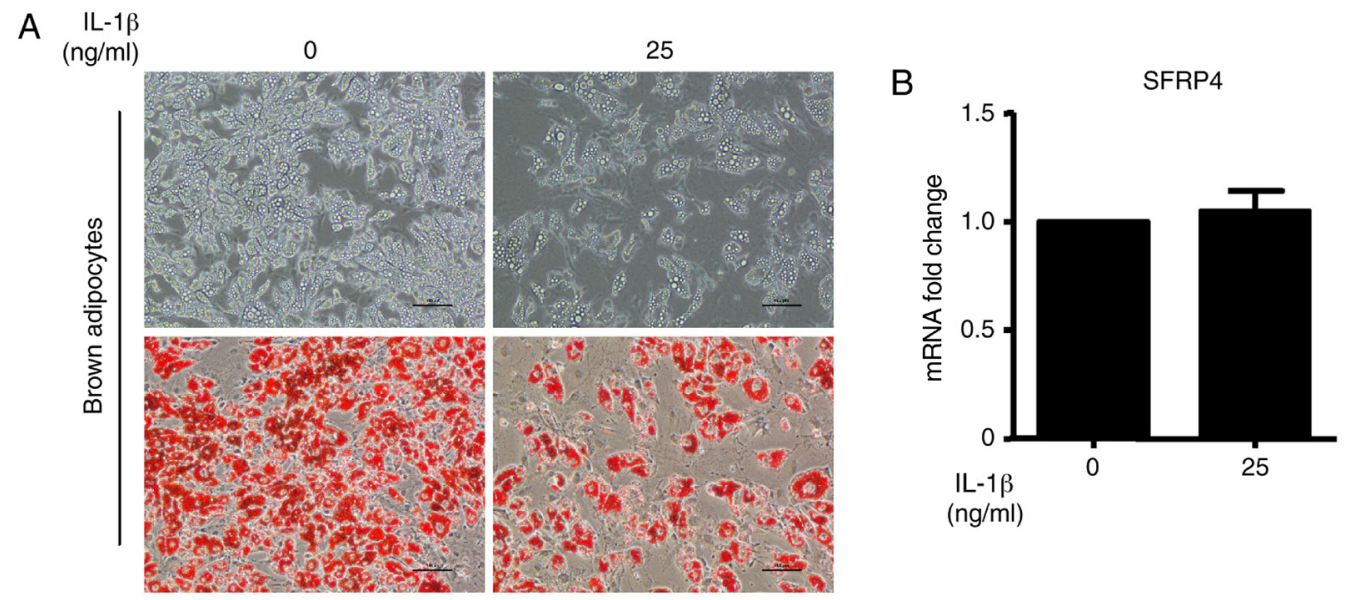

Figure 5. Brown preadipocytes incubated with IL-1 $\beta$ during maintenance and differentiation at a concentration of $25 \mathrm{ng} / \mathrm{ml}$. (A) Photomicrographs show Oil Red O staining of cells on day 8 of differentiation. Magnification, x200. The upper images show the cell morphology captured with inverted phase contrast microscopy. To evaluate the accumulation of lipid droplets during brown adipocyte differentiation, Oil Red O staining was performed and the images are

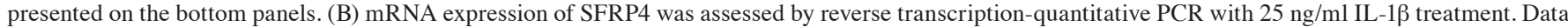
are expressed as the mean \pm SEM. $n=4$ for each group. IL-1 $\beta$, interleukin-1 $\beta ;$ SFRP4, secreted frizzled related protein 4.
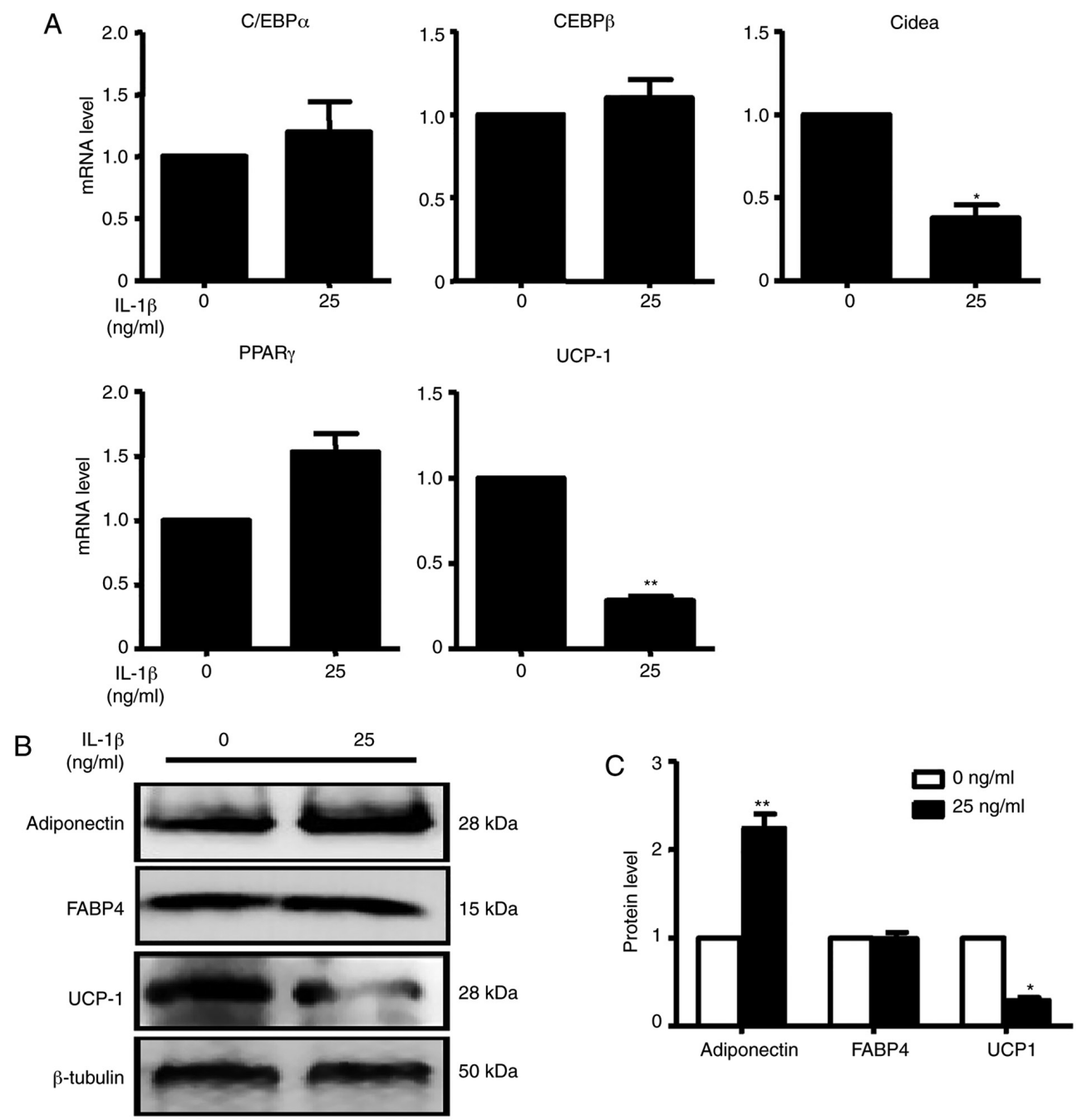

Figure 6. IL-1 $\beta$ inhibits the mRNA and protein expression of adipogenic markers. (A) C/EBP $\alpha, C / E B P \beta$, Cidea, PPAR $\gamma$ and UCP-1 were assessed by reverse transcription-quantitative PCR. At the concentration of $25 \mathrm{ng} / \mathrm{ml} \mathrm{IL-1 \beta ,C/EBP} \alpha, \mathrm{C} / \mathrm{EBP} \beta$ and PPAR $\gamma$ were not changed compared with the absence of IL-1 $\beta$. Cidea and UCP-1 mRNA expression levels were all significantly decreased in the presence of IL-1 $\beta$ compared with the absence of IL- $1 \beta$. (B) Adiponectin, FABP4 and UCP-1 were analysed by western blotting. (C) Quantification of western blotting analysis. With the treatment of IL-1 $\beta$, adiponectin protein expression was significantly increased with the treatment of IL-1 $\beta$. UCP-1 protein expression was decreased 0.5 -fold compared with the absence of IL-1 $\beta$. Data are expressed as the mean \pm SEM. $n=4$ for each group. ${ }^{\mathrm{P}}<0.05 ;{ }^{* *} \mathrm{P}<0.01$ vs. control. UCP-1, uncoupling protein $1 ; \mathrm{C} / \mathrm{EBP} \alpha / \beta, \mathrm{CCAAT} / \mathrm{enhancer-binding}$ protein $\alpha / \beta$; Cidea, cell death-inducing dffa-like effector a; PPAR $\gamma$, peroxisome proliferator-activated receptor $\gamma$; FABP4, fatty acid-binding protein 4 . 


\section{Discussion}

As the worldwide rates of obesity and associated metabolic disorders have increased, better understanding of the fundamental mechanisms underlying adipocyte formation and fat tissue expansion is required (18). The present study demonstrated increasing expression pattern of SFRP4 in mouse preadipocytes during differentiation. In brown preadipocytes, incubation with gradient doses of SFRP4 (0, 1, 10 and $100 \mathrm{ng} / \mathrm{ml}$ ) promoted the formation of lipid droplets in brown adipocytes by morphological observation. Furthermore, it was discovered that high-dose SFRP4 significantly accelerated the thermogenic metabolism of brown adipocytes by regulating the secretion of leptin and adiponectin. Additionally, the potential of IL-1 $\beta$ as an upstream factor to regulate SFRP4 expression in brown adipocytes was investigated. The results showed that in addition to inhibiting the differentiation of brown adipocytes, IL-1 $\beta$ has no effect on the expression of SFRP4.

BAT is the main source of non-shivering thermogenesis and heat production in mammals, containing a large number of mitochondria with strong oxidation capacity (19). UCP-1, existing in the inner membrane of mitochondria and providing heat for cells in the form of an uncoupled respiratory chain, is expressed specifically in brown adipocytes (5). In rodents, brown adipocytes are found in specific brown adipocyte depots, such as the scapula, neck and the chest of mice (20). In addition to heat production, BAT also has some physiological functions. Firstly, the thermogenic activity of BAT can be added to the clearance of triglycerides in plasma, regulate the homeostasis of vascular lipoproteins, and effectively alleviate the formation of atherosclerotic plaques (21). Secondly, BAT allows the body adapt to the cold external environment and promotes energy consumption to prevent obesity and type 2 diabetes (22). According to this characteristic of BAT, the excess energy stored is consumed spontaneously, which was also applicable to BAT transplantation individuals (23). Thirdly, as an endocrine organ in the mammalian body, in addition to adipocytokine secretion, brown adipocytes also regulate the inflammatory response of the body by secreting inflammatory factors to the extracellular space (24). In the present study, it was found that SFRP4 promoted brown adipocyte differentiation, indicating that overexpression of SFRP4 significantly increased the number of mature brown adipocytes in the brown adipose depot, which is conducive to maintaining endocrine homeostasis and energy metabolism balance in mice.

In the present study, the SFRP4 expression pattern was ' $S$ ' style during the brown adipocyte differentiation, as the SFRP4 mRNA expression was increased at day 0, decreased at day 2, then increased again from day 2 to day 8 following the brown adipocyte differentiation; which was an interesting phenomenon worthy of attention. Firstly, the preadipocytes were seeded in dishes and the time point was set as day-4, and the cell density was $\sim 70 \%$. After incubation for two days, the cells proliferated to $\sim 80-90 \%$ at day- 2 . At time point 0 , the cells proliferated and fused to differentiate into mature adipocytes. It was speculated that in the cell proliferation phase, SFRP4 promoted cell proliferation. However, at days 0 to 4 , induction medium was added to induce cell differentiation, and the preadipocytes exhibited contact inhibition and cell proliferation arrest. The expression of SFRP4 had no effect on cell differentiation at the early stage. It was noteworthy that on days 6 to 8, the brown adipocytes differentiated into mature adipocytes and formed lipid droplets, and SFRP4 promoted brown adipocyte differentiation and lipid formation.

It has been confirmed that PPAR $\gamma$, as a marker gene of adipocyte differentiation, is not only essential for the development of all types of adipocytes but also plays an important role in the process of adipocyte de novo differentiation (25). Moreover, PPAR $\gamma$ increases the capacity of mitochondria and the potential for uncoupling, promoting the browning of white adipocytes (26). Based on this, C/EBP family members play a major role in maintaining PPAR $\gamma$ expression and coregulating transcription to intensify and maintain adipocyte differentiation (27). A previous study reported that the absence of $\mathrm{C} / \mathrm{EBP} \alpha$ in mice prevents the development of white adipocytes and has no effect on brown adipocyte formation, which suggests that the absence of $\mathrm{C} / \mathrm{EBP} \alpha$ may be compensated by upregulating the expression of $\mathrm{C} / \mathrm{EBP} \beta$ in brown adipose tissue (28). However, the present study confirmed that overexpression of SFRP4 promoted C/EBP $\alpha$ and $\mathrm{C} / \mathrm{EBP} \beta$ expression in brown adipocytes rather than PPAR $\gamma$.

Importantly, Seale et al (29) demonstrated that zinc-finger protein PRDM16 is highly expressed in BAT compared with the WAT and activated the brown adipocyte identity by direct binding to PGC- $1 \alpha$ and PGC-1 $\beta$ to control the determination of brown adipocyte fate. Meanwhile, the expression level of PGC-1 $\alpha$ was elevated upon cold exposure and controlled mitochondrial biogenesis and respiration regulated by UCP-1 (30). Specifically, overexpression of PGC-1 $\alpha$ promoted the brown adipocyte phenotype formation (31).

In Fig. 3 , after incubation with SFRP4, the $\mathrm{C} / \mathrm{EBP} \alpha, \mathrm{C} / \mathrm{EBP} \beta$, Cidea and GLUT4 mRNA expression levels were significantly increased. However, only PPAR $\gamma$ and adiponectin mRNA expression were unchanged with SFRP4 treatment. Firstly, as previously reported, $\mathrm{C} / \mathrm{EBP} \alpha$ and $\mathrm{C} / \mathrm{EBP} \beta$ are adipocyte markers used to evaluate differentiation (32). In the present study, it was demonstrated that $\mathrm{C} / \mathrm{EBP} \alpha$ and $\mathrm{C} / \mathrm{EBP} \beta$ were increased significantly after incubation with SFRP4 (10 and $100 \mathrm{ng} / \mathrm{ml}$ ). Secondly, Cidea, a lipid droplet-associated protein, was highly expressed after induction by high concentrations of recombinant SFRP4 in the present study. Additionally, Cidea specifically strengthened and regulated the transcription of UCP-1 in the nucleus of human fat cells (33). Thirdly, in the present study, the mRNA expression of PPAR $\gamma$ and adiponectin were measured in mature brown adipocytes at day 8 . It was speculated that PPAR $\gamma$ was expressed at the early stage of brown adipocyte differentiation, and no difference in PPAR $\gamma$ mRNA expression could be detected at the terminal differentiation stage of brown adipocytes. Despite the statement that SFRP4 promotes brown adipocyte differentiation in vitro was strong, additional in vivo experiments were needed to elucidate the potential mechanism of this subject in the future.

As an important endocrine organ, BAT secretes several types of adipocytokines, such as leptin and adiponectin, to participate in physiological metabolism (34). Leptin, an important secretory protein, regulates food intake and energy consumption (35). For example, Wang et al (36) discovered that leptin promoted the browning of white adipocytes by inhibiting the Hh signalling pathway to decrease obesity in mice. In terms of energy balance, leptin also maintains the thermogenesis of brown adipocytes to 
achieve a steady state and further participate in and support the regulation of brown adipocytes in energy balance (37), which was consistent with the present finding that a high concentration of SFRP4 significantly upregulated the expression of leptin secretion. In contrast, as a polypeptide hormone, a previous study revealed that adiponectin decreases thermogenesis by inhibiting the activity of BAT in mice (38), which was sufficient to explain why even low-dose SFRP4 treatment significantly inhibited the secretion of adiponectin in brown adipocytes. Obviously, the mRNA expression of adiponectin was not consistent with protein expression after treatment with SFRP4 in brown adipocytes.

Gene expression regulation is complex and changeable, especially during dynamic transition (39). The mRNA encoding protein undergoes transcription, translation and posttranslational processes; however, the spatiotemporal variability of genes and the limitation of protein biosynthesis resources strongly affect the association between protein levels and their encoded transcripts (40).

There are many comorbidities of obesity, including chronic and low-grade systemic inflammation, increased adipose tissue, fatty cell hypertrophy and hyperplasia (17). The local infiltration of immune cells and the release of proinflammatory cytokines decrease the activity of metabolism in obese patients (41). Brown adipocytes are responsible for energy consumption and are less prone to local inflammation compared with white adipocytes; however, strong damage from obesity eventually leads to a local BAT proinflammatory environment, which directly changes the thermogenic activity of brown adipocytes, impairs the energy consumption mechanism and fuel matrix glucose uptake (42). There is evidence that IL-1 $\beta$ significantly downregulated the expression of UCP-1 when incubated with brown adipocytes (43). Moreover, IL-1 $\beta$ derived from macrophages significantly inhibited the expression of UCP-1 in C3H10T1/2 cells (38), which was consistent with the present findings. Previous studies have confirmed that the release of SFRP4 in islets is stimulated by the inflammatory marker IL-1 $\beta$, which provides an association between islet inflammation and impaired insulin secretion (11). However, IL-1 $\beta$ had no contribution to the stimulation of SFRP4 expression in brown adipocytes in the present study, revealing that brown and white adipocytes are heterogeneous and that the expression patterns are quite different (44).

In summary, the present study identified and characterized the role of SFRP4, a secreted inhibitor of Wnt signalling, in various functions in different types of adipose tissue expansion. Future studies demonstrated that the inflammatory factor IL-1 $\beta$ has no effect on SFRP4 expression and secretion in brown adipocytes. Collectively, the present data support the concept that SFRP4 regulates murine brown adipocyte differentiation.

\section{Acknowledgements}

Not applicable.

\section{Funding}

This work was supported by grants from National Natural Science Foundation of China (grant no. 81900399), Natural Science Foundation Project of Shaanxi Province (grant nos. 19JS060 and 2016JM8122), State Administration of Traditional Chinese Medicine of Shaanxi Province (grant no. 2019-ZZ-JC034) and the Key Research and Development Plan of Shaanxi Province (grant no. 2018SF-266).

\section{Availability of data and materials}

The datasets used and/or analyzed during the current study are available from the corresponding author on reasonable request.

\section{Authors' contributions}

HG, LX, EL and QY confirm the authenticity of all the raw data. HG, HYZ and AX performed the experiments. YL and LX analyzed the data. HG, EL and QY designed the study and wrote the manuscript. JZ and HDZ performed the RT-qPCR and analysis of the data in the revision manuscript. All authors read and approved the final manuscript.

\section{Ethics approval and consent to participate}

The Laboratory Animal Administration Committee of Xi'an Medical University approved all animal experiments (Institutional Animal Care and Use Committee; approval no. XYJZS 201806025-8).

\section{Patient consent for publication}

Not applicable.

\section{Competing interests}

The authors declare that they have no competing interests.

\section{References}

1. Murawska-Cialowicz E: Adipose tissue-morphological and biochemical characteristic of different depots. Postepy Hig Med Dosw (Online) 71: 466-484, 2017.

2. Cinti S: The adipose organ at a glance. Dis Model Mech 5: 588-594, 2012.

3. Ibrahim MM: Subcutaneous and visceral adipose tissue: Structural and functional differences. Obes Rev 11: 11-18, 2010.

4. Marlatt KL and Ravussin E: Brown adipose tissue: An update on recent findings. Curr Obes Rep 6: 389-396, 2017.

5. Yu Q, Wang F, Meng X, Gong Y, Wang Y, Xu C and Wang S: Short-term use of atorvastatin affects glucose homeostasis and suppresses the expression of LDL receptors in the pancreas of mice. Mol Med Rep 18: 2780-2788, 2018.

6. Virtanen KA, Lidell ME, Orava J, Heglind M, Westergren R, Niemi T, Taittonen M, Laine J, Savisto NJ, Enerbäck S and Nuutila P: Functional brown adipose tissue in healthy adults. N Engl J Med 360: 1518-1525, 2009.

7. Ode KL, Frohnert BI and Nathan BM: Identification and treatment of metabolic complications in pediatric obesity. Rev Endocr Metab Disord 10: 167-188, 2009.

8. Pawar NM and Rao P: Secreted frizzled related protein 4 (sFRP4) update: A brief review. Cell Signal 45: 63-70, 2018.

9. Mastaitis J, Eckersdorff M, Min S, Xin Y, Cavino K, Aglione J, Okamoto H, Na E, Stitt T, Dominguez MG, et al: Loss of SFRP4 alters body size, food intake and energy expenditure in diet-induced obese male mice. Endocrinology 156: 4502-4510, 2015.

10. Liu F, Qu H, Li Y, Tang Q, Yang Z, Wang H and Deng H: Relationship between serum secreted frizzled-related protein 4 levels and the first-phase of glucose-stimulated insulin secretion in individuals with different glucose tolerance. Endocr J 62: 733-740, 2015. 
11. MahdiT,Hänzelmann S,Salehi A,Muhammed SJ, ReinbotheTM, Tang Y, Axelsson AS, Zhou Y, Jing X, Almgren P, et al: Secreted frizzled-related protein 4 reduces insulin secretion and is overexpressed in type 2 diabetes. Cell Metab 16: 625-633, 2012.

12. Li XJ, Yang H, Li GX, Zhang GH, Cheng J, Guan H and Yang GS: Transcriptome profile analysis of porcine adipose tissue by high-throughput sequencing. Anim Genet 43: 144-152, 2012.

13. Guan H, Zhang Y, Gao S, Bai L, Zhao S, Cheng XW, Fan J and Liu E: Differential patterns of secreted frizzled-related protein 4 (SFRP4) in adipocyte differentiation: Adipose depot specificity. Cell Physiol Biochem 46: 2149-2164, 2018.

14. Gao W, Kong X and Yang Q: Isolation, primary culture, and differentiation of preadipocytes from mouse brown adipose tissue. Methods Mol Biol 1566: 3-8, 2017.

15. Barthold SW, Bayne KA, Davis MA,EverittJI,Fox JG, Garnett NL, Gauda EB, Kemnitz JW, Clark JAM, McClintock MK, et al: Guide for the care and use of laboratory animals. 8th edition. National Institutes of Health (NIH), 2008.

16. Frontini A and Cinti S: Distribution and development of brown adipocytes in the murine and human adipose organ. Cell Metab 11: 253-256, 2010

17. Alomar SY, Zaibi MS, Kępczyńska MA, Gentili A, Alkhuriji A, Mansour L, Dar JA and Trayhurn P: PCR array and protein array studies demonstrate that IL-1 $\beta$ (interleukin-1 $\beta$ ) stimulates the expression and secretion of multiple cytokines and chemokines in human adipocytes. Arch Physiol Biochem 121: 187-193, 2015.

18. Withrow D and Alter DA: The economic burden of obesity worldwide: A systematic review of the direct costs of obesity. Obes Rev 12: 131-141, 2011

19. Hankir MK: Loading and firing the brown adipocyte. Adipocyte 7 4-11, 2018.

20. Giralt M and Villarroya F: White, brown, beige/brite: Different adipose cells for different functions? Endocrinology 154 2992-3000, 2013.

21. Xiong W, Zhao X, Villacorta L, Rom O, Garcia-Barrio MT, Guo Y, Fan Y, Zhu T, Zhang J, Zeng R, et al: Brown adipocyte-specific PPAR $\gamma$ (peroxisome proliferator-activated receptor $\gamma$ ) deletion impairs perivascular adipose tissue development and enhances atherosclerosis in mice. Arterioscler Thromb Vasc Biol 38: 1738-1747, 2018.

22. Scheideler M, Herzig S and Georgiadi A: Endocrine and autocrine/paracrine modulators of brown adipose tissue mass and activity as novel therapeutic strategies against obesity and type 2 diabetes. Horm Mol Biol Clin Investig: Aug 29, 2017 (Epub ahead of print). doi: 10.1515/hmbci-2017-0043

23. White JD, Dewal RS and Stanford KI: The beneficial effects of brown adipose tissue transplantation. Mol Aspects Med 68: 74-81, 2019.

24. Villarroya F, Cereijo R, Villarroya J and Giralt M: Brown adipose tissue as a secretory organ. Nat Rev Endocrinol 13: 26-35, 2017.

25. Tsai YS and Maeda N: PPARgamma: A critical determinant of body fat distribution in humans and mice. Trends Cardiovasc Med 15: 81-85, 2005.

26. Nedergaard J, Petrovic N, Lindgren EM, Jacobsson A and Cannon B: PPARgamma in the control of brown adipocyte differentiation. Biochim Biophys Acta 1740: 293-304, 2005.

27. Ramji DP and Foka P: CCAAT/enhancer-binding proteins: Structure, function and regulation. Biochem J 365: 561-575, 2002.

28. Yubero P, Manchado C, Cassard-Doulcier AM, Mampel T, Vinas O, Iglesias R, Giralt M and Villarroya F: CCAAT/enhancer binding proteins alpha and beta are transcriptional activators of the brown fat uncoupling protein gene promoter. Biochem Biophys Res Commun 198: 653-659, 1994.
29. Seale P, Kajimura S, Yang W, Chin S, Rohas LM, Uldry M, Tavernier G, Langin D and Spiegelman BM: Transcriptional control of brown fat determination by PRDM16. Cell Meta 6: 38-54, 2007.

30. Puigserver P, Wu Z, Park CW, Graves R, Wright $\mathrm{M}$ and Spiegelman BM: A cold-inducible coactivator of nuclear receptors linked to adaptive thermogenesis. Cell 92: 829-839, 1998.

31. Tiraby C, Tavernier G, Lefort C, Larrouy D, Bouillaud F, Ricquier D and Langin D: Acquirement of brown fat cell features by human white adipocytes. J Biol Chem 278: 33370-33376, 2003.

32. Kiess W, Petzold S, Töpfer M, Garten A, Blüher S, Kapellen T, Körner A and Kratzsch J: Adipocytes and adipose tissue. Best Pract Res Clin Endocrinol Metab 22: 135-153, 2008.

33. Jash S, Banerjee S, Lee MJ, Farmer SR and Puri V: CIDEA transcriptionally regulates UCP1 for britening and thermogenesis in human fat cells. iScience 20: 73-89, 2019.

34. Villarroya J, Cereijo R, Gavalda-Navarro A, Peyrou M, Giralt M and Villarroya F: New insights into the secretory functions of brown adipose tissue. J Endocrinol 243: R19-R27, 2019.

35. Paz G, Mastronardi CA and Licinio J: Leptin treatment: Facts and expectations. Metabolism 64: 146-156, 2015.

36. Wang J, Ge J, Cao H, Zhang X, Guo Y, Li X, Xia B, Yang G and Shi X: Leptin promotes white adipocyte browning by inhibiting the HH signaling pathway. Cells 8: 372, 2019.

37. Pandit R, Beerens S and Adan RAH: Role of leptin in energy expenditure: The hypothalamic perspective. Am J Physiol Regul Integr Comp Physiol 312: R938-R947, 2017.

38. Qiao L, Yoo HS, Bosco C, Lee B, Feng GS, Schaack J, Chi NW and Shao J: Adiponectin reduces thermogenesis by inhibiting brown adipose tissue activation in mice. Diabetologia 57: 1027-1036, 2014

39. Song G, Zong C, Zhang Z, Yu Y, Yao S, Jiao P, Tian H, Zhai L, Zhao H, Tian S, et al: Molecular hydrogen stabilizes atherosclerotic plaque in low-density lipoprotein receptor-knockout mice. Free Radic Biol Med 87: 58-68, 2015.

40. Jing L, Wang Y, Zhao XM, Zhao B, Han JJ, Qin SC and Sun XJ: Cardioprotective effect of hydrogen-rich saline on isoproterenol-induced myocardial infarction in rats. Heart Lung Circ 24: 602-610, 2015.

41. Stolarczyk E: Adipose tissue inflammation in obesity: A metabolic or immune response? Curr Opin Pharmacol 37: 35-40, 2017.

42. Villarroya F, Cereijo R, Gavalda-Navarro A, Villarroya J and Giralt M: Inflammation of brown/beige adipose tissues in obesity and metabolic disease. J Intern Med 284: 492-504, 2018

43. Nøhr MK, Bobba N, Richelsen B, Lund S and Pedersen SB: Inflammation downregulates UCP1 expression in brown adipocytes potentially via SIRT1 and DBC1 interaction. Int J Mol Sci 18: 1006, 2017.

44. Goto T, Naknukool S, Yoshitake R, Hanafusa Y, Tokiwa S, Li Y, Sakamoto T, Nitta T, Kim M, Takahashi N, et al: Proinflammatory cytokine interleukin-1 $\beta$ suppresses cold-induced thermogenesis in adipocytes. Cytokine 77: 107-114, 2016.

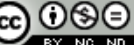

This work is licensed under a Creative Commons Attribution-NonCommercial-NoDerivatives 4.0 International (CC BY-NC-ND 4.0) License. 